\title{
The Interplay between Educational Achievement, Occupational Success, and Well-Being
}

\author{
Robin Samuel • Manfred Max Bergman • Sandra Hupka-Brunner
}

Accepted: 19 December 2011/Published online: 5 January 2012

(C) Springer Science+Business Media B.V. 2012

\begin{abstract}
Many studies have examined the effect of life events, education, and income on well-being. Conversely, research concerning well-being as a predictor of life course outcomes is sparse. Diener's suggestion "to inquire about the effects of well-being on future behavior and success" has, with some exceptions, not yet come to fruition. This article contributes to this body of research. We conceptualize and analyze the interplay between educational achievement, occupational success, and well-being as a complex process. The relationship between these domains is examined drawing on a structure-agency framework derived from Bourdieu and Social Comparison Theory. Social comparison between adolescents and their parents is suggested to be the mechanism explaining the effects of successful and unsuccessful intergenerational transmission of educational achievement and occupational success on well-being. It is further argued that well-being may serve as an individual resource by fostering educational and occupational outcomes. Panel data from the Transition from Education to Employment (TREE) project, a Swiss PISA 2000 followup study, was used. The interplay between well-being and successful and unsuccessful intergenerational transfer of educational attainment was analyzed in an autoregressive
\end{abstract}

M. M. Bergman is a Visiting Professor at the Universities of Johannesburg and the Witwatersrand.

R. Samuel $(\bowtie) \cdot$ M. M. Bergman

Chair of Social Research and Methodology, Department of the Social Sciences, University of Basel,

Petersgraben 27, 4051 Basel, Switzerland

e-mail: robin.samuel@unibas.ch

M. M. Bergman

e-mail: max.bergman@unibas.ch

M. M. Bergman

University of Johannesburg, Johannesburg, South-Africa

M. M. Bergman

University of the Witwatersrand, Johannesburg, South-Africa

S. Hupka-Brunner

Chair of Social Research and Methodology, Department of the Social Sciences, TREE-Transition from Education to Employment, University of Basel, Petersgraben 27, 4051 Basel, Switzerland e-mail: sandra.hupka@unibas.ch 
cross-lagged mixture model framework. Social comparison was found to be related to well-being, while well-being proved to significantly increase the probability of successful intergenerational transfer of educational attainment.

Keywords Educational achievement · Occupational success · Well-being · Cultural capital $\cdot$ Longitudinal analysis

\section{Introduction}

Educational and occupational success and well-being may be thought of as forming a reciprocal relationship. On the one hand, educational and occupational success of adolescents may affect their well-being. Successful mastery of a training program or attainment of occupational goals, for example, may affect well-being positively. In this case, evaluations of one's achievement may affect well-being. On the other hand, well-being may be conceptualized as a personal resource itself, affecting educational and occupational success. A positive attitude toward life, for example, may lead a person to enroll in a demanding training program, and it may support successful completion. The experience of a successful accomplishment may then, in turn, increase an adolescent's positive attitude toward life. This reciprocity is likely to be affected by social and personal resources. In a number of studies, parents' status or individual educational level were found to affect educational and occupational success (Blau and Duncan 1967; Bourdieu and Passeron 1970; Erikson and Goldthorpe 1992) and well-being (Desjardins 2008; Michalos 2008). Furthermore, cognitive skills and gender appear to explain differences in educational and occupational success and well-being in complex ways (Kroll 2010; Tesch-Römer et al. 2007).

In this paper, we examine this reciprocity over time. First, we analyze how success or failure affects well-being in the context of transition to adulthood. Second, we outline, how success or failure are affected by background factors, and how well-being contributes to successful educational and occupational outcomes. Third, we explore how the reciprocal relationship between educational and occupational success and well-being itself is affected by factors such as cultural capital and gender.

We draw on two different approaches to frame the reciprocity: (1) Social Comparison Theory (Festinger 1954; Gibbons and Buunk 1999) to explain effects of success or failure on well-being. Within social comparison theory, two competing theoretical approaches are presented and discussed. (2) Bourdieuian capital theory (Bourdieu and Passeron 1970; Bourdieu 1979) will provide the framework to explain success and failure.

Panel data from approximately 6,000 young Swiss persons who left compulsory schooling in 2000 will be used. The proposed reciprocal relationship will then be analyzed over 6 years in an autoregressive cross-lagged mixture model framework.

\section{Theoretical Framework}

\subsection{Effects of Educational Achievement and Occupational Success on Well-Being}

Educational achievement and occupational success are likely to affect adolescents' wellbeing. For example, Samuel et al. (2011) found long-term aggregate effects of successful and unsuccessful intergenerational transfer of educational attainment on the stability of well-being. One explanatory mechanism was the inertia of the habitus as conceptualized by 
Bourdieu (1979). This finding provides some empirical evidence for Lipset and Bendix' (1959: 286) assumption concerning adverse effects of identity inconsistencies caused by educational and occupational mobility on well-being. In this article, we argue that shortterm effects, i.e. on a yearly basis, of educational and occupational success on well-being are also observable. We propose social comparison as an explanatory mechanism.

In light of globalization, individualization, and pluralized educational and occupational pathways (Bradley and Nguyen 2004; Buchholz et al. 2009; Crisholm and Hurrelmann 1995 ) it has become increasingly difficult to determine what adolescent educational and occupational success is. In this article, we argue that success, as well as well-being (Tatarkiewicz 1976), is a relational construct: an individual's educational or occupational success is relative to a point of reference or to a system of points of reference. There are at least two ways to explore this relativity. First, it can be viewed from a perspective of the adolescents' subjective evaluation of discrepancies, e.g. of what one has and what one wants to have, or what significant others have, as in Michalos' Multiple Discrepancies Theory (1985; cf. also Blore et al. 2011) or as discussed in the literature on goal attainment (e.g., Carver and Scheier 1990). Second, it can be regarded from a structural perspective, by comparing how adolescents' educational and occupational success differs from, e.g. norms and socioeconomic background as discussed in a number of sociological theories (Blossfeld and Shavit 1993; Bourdieu and Passeron 1970; Erikson and Goldthorpe 1992; Shavit and Müller 1998). In this paper, we apply the second perspective. Thus, from this point of view, youths with high levels of personal and social resources, e.g. those who have high grades and who have wealthy and well-educated parents, may be deemed successful only if they match or surpass their parents in terms of educational achievement (Bourdieu and Passeron 1996). Only the latter, that is, surpassing one's parents' educational achievement, is considered as a success when accounting for educational expansion (Erikson and Goldthorpe 1992; Shavit and Blossfeld 1993). By contrast, youths with low levels of personal and social resources, e.g. those who have low grades, no formal certificates, and unskilled parents, may be deemed successful if they have acquired a permanent labor contract and have a regular income.

Conceptually, we propose at least four different points of reference with regard to educational and occupational success: (1) norms; these may include the duration of educational programs and educational pathways (sequences of educational programs) as prescribed by institutions and policies, but also general norms, such as having obtained at least a certificate from an upper secondary institution (e.g., vocational education training or academic high school), (2) peers, in terms of their educational and occupational achievement, (3) family members (e.g., parents and siblings), and (4) the individual himself/herself, in terms of intra-individual comparisons with previous episodes of success and failure.

This approach seems attractive as it provides a multidimensional understanding of success from a social comparison perspective. If this is put to a series of empirical tests, different problems are likely to occur. It would be difficult to resolve how norms are functional for different individuals. Furthermore, during the transition to adulthood, adolescents' peers are likely to be rather homogenous in terms of temporal and hierarchical position within the respective educational and occupational settings. Certainly, the mechanisms of social comparison are still at play, e.g., with regard to skills, opinions, and abilities (for an overview see Suls and Wheeler 2000), but will not yield too many differences concerning educational and occupational positions. Moreover, in particular specific educational norms and extensive data on peers are rarely contained in standard data sets. In this article, we will thus focus on comparisons to family members and the self. 
The general tendency to compare oneself to objective or social standards was described in Merton and Kitt's Reference Group Theory (1950) and Festinger's Social Comparison Theory (1954). Psychologically, social comparisons may be driven by needs for selfevaluation (Festinger 1954), self-enhancement (cf. Wills 1981), or self-improvement (Wilson and Benner 1971). Most generally, the effects of social comparison on well-being are believed to be intrinsic to its direction (cf. Boes et al. 2010). That is, upward comparison decreases and downward comparison increases well-being. For example, educationally upwardly mobile adolescents might compare their educational position to their low-educated parents. As noted by Havighurst et al. (1962), upward mobility may then be considered as a successful achievement and fulfillment of parental aspirations (Bourdieu and Passeron 1996). This leads to well-being and increases the likelihood of successful coping in a person's educational and occupational career (Evans 1994; Grob et al. 1996). Especially in neo-Social Comparison Theory, it is postulated that downward comparison comprises a coping function: People tend to make downward comparisons to feel better (Suls and Wheeler 2000; Wills 1981). However, downward comparison does not have to be conceived of as a coping strategy (Lazarus and Folkman 1984; Tennen and Affleck 1997). Another strand of literature proposes that the effects of social comparison on well-being are not intrinsic to their direction. As Buunk et al. (1990) found, it may be too simplistic to assume that upward comparison leads to negative effects for well-being, whereas downward comparison boosts well-being levels. For example, upward comparison contains "at least two pieces of information: (a) that you are not as well off as everyone and (b) that it is possible for you to be better than you are at present" (Buunk et al. 1990: 1239). Downward comparison contains analogous information. A variety of factors, e.g., traits and sociodemographic characteristics, seem to moderate these effects, i.e., whether a person compares upward or downward, and how this choice, made consciously or unconsciously, affects well-being (Crocker et al. 1987; Gibbons and Buunk 1999). This literature proposes social comparison to produce contrastive and assimilative outcomes. That is, "the affective consequences of a comparison are not intrinsic to its direction" (Buunk et al. 1990: 1239).

In this sense, there is disagreement as to how differences in success affect well-being via social comparison. One strand of the literature posits contrastive outcomes, i.e., being more successful than significant others will boost well-being levels while being less successful than significant others will decrease well-being. Another strand postulates contrastive and assimilative outcomes, i.e., regardless of the direction of comparison, wellbeing may increase or decrease. In this paper, we will test whether there is empirical evidence for the former position. Accordingly, we hypothesize that:

$\mathbf{H}_{1}$ Adolescents' success differentials produce contrastive well-being outcomes over time.

\subsection{Effects of Well-Being on Educational Achievement and Occupational Success}

Many theories attempt to explain why people are more or less likely to be successful in comparison to their parents. In some studies, social inheritance of advantages, i.e., intergenerational transfer of, for instance, educational attainment is offered as an explanation. Educational attainment and occupational status were found to be largely dependent on social background (Blau and Duncan 1967; Breen 2004; Breen and Goldthorpe 1997), although the exact underlying mechanisms of social reproduction remain vague. Bourdieu (1977) argues that most parents aim to transfer their own socio-economic status to their offspring, and children often use these aspirations as personal guidelines. In this sense, 
the focus is on the transfer, accumulation, and conversion of economic, cultural, and social capital in the form of social and personal resources. However, less is known about the relevance of well-being to life course outcomes such as educational and occupational success. For example, Bradburn (1969) argued that well-being may be a general potential to cope with challenging life situations. The neglected state of this perspective in current well-being research is also observed by Diener, who suggests examining "effects of wellbeing on future behavior and success" (2009: 268). In this section of the paper, we will outline how well-being may be conceptualized as an individual resource, contributing to educational and occupational outcomes.

Only recently were the predictive qualities of well-being for specific areas of life examined. In a meta-analysis, Lyubomirsky et al. (2005) reviewed studies which implied causal relationships between happiness, i.e., long-term propensity to frequently experience positive emotions, and successful outcomes. They reported weighted mean effect sizes in the longitudinal studies ranging from 0.05 to 0.29 for different areas such as work, life, and health $(\mathrm{n}=62)$. In the area of health, for example, Xu (2005) found some evidence that subjective well-being (SWB) has protective effects against different forms of mortality, while similarly, Diener and Chan (2011) conclude "that the evidence for the influence of SWB on health and all-cause mortality is clear and compelling" (2011: 32). Studies examining the effects of well-being on educational and occupational success during adolescence are even rarer. Roberts et al. (2003) analyzed the relationship between the personality and work of young adults from 18 to 26 and found reciprocal relations between these domains. Proctor et al. (2010) found that life satisfaction was positively associated with educational success and a series of interpersonal and intrapersonal variables, such as parental relations and self-esteem, respectively. In the context of adolescence and postcompulsory pathways, Eckersley et al. found well-being to affect the likelihood of employment and level of remuneration (2006: 24).

In summary, there is some evidence in the literature that well-being may predict educational and occupational outcomes in adolescence. Thus, we conceptualize well-being as an individual resource that has a positive effect on educational and occupational success. Together with social and other personal factors, well-being may contribute to quasiobjective success in the form of educational and occupational upward mobility. Accordingly, we hypothesize:

$\mathbf{H}_{2}$ Well-being is positively associated with the probability of being successful.

\subsection{Effects of Social Background and Personal Resources on Well-Being and Educational Achievement and Occupational Success}

In the context of the transition to adulthood, educational and occupational success not only depends on well-being, but also on other factors such as cognitive skills and social background. In turn, these factors are also likely to affect well-being. The reciprocal process between well-being and success is in itself dependent on a group of background factors. Some of them will be more directly related to well-being, others more to educational success. Through the proposed reciprocity of the relationship, all factors are related at least indirectly to well-being or success. In the following section, we outline how some of the most important social and personal factors contribute to the interplay.

Social background may be theorized to include different forms of capital (Bourdieu 1979). Economic capital is represented by and convertible into money. It allows parents to pay for tutoring and private schools. Moreover, economic capital allows adolescents to 
enroll in lengthy training programs and university as there is no or little need for additional income (Bourdieu 2001; Bradley and Nguyen 2004). Social and symbolic capital were found to be positively associated with knowledge about the functioning and structures of the educational system and finding dual vocational education and training (VET) ${ }^{1}$ positions (Haeberlin et al. 2004). Cultural capital represents non-economic resources that are mostly influential on educational achievement and are subdivided into three forms: embodied in the individual in the form of cultural capital that is linked to knowledge and ability (including investment and commitment to learning, education, and self-improvement); objectified in cultural goods, such as books, paintings, instruments; and institutionalized through professional and academic credentials and qualifications. Families with high levels of cultural capital are likely to provide enriched learning environments for their offspring. There is also evidence that cultural capital affects SWB positively (Kim and Kim 2008). These different forms of Bourdieuian capital can be exchanged and converted with each other. Importantly, high levels of one form of capital do not necessarily imply high levels of other forms of capital. For example, a family may possess much economic capital but lack cultural capital. Their offspring may still attend university, but is less likely to excel. This example shows, that the composition and structure of different forms of capital matters (Krais 1983). Generally, families high in capital are likely to have offspring with high educational and professional aspirations and the resources to accommodate the relevant requirements.

Among the strongest individual predictors of educational and occupational success is embodied cultural capital (Bourdieu and Passeron 1970). This includes different cultural abilities, such as reading literacy. It is considered as the basis for other forms of literacy, e.g., math and computer literacy. Reading competency was found to include a variety of other skills and to form positive feedback relations with other cognitive skills (Bast and Reitsma 1998; Stanovich 1986). Reading literacy and math literacy are indicative of education levels and are highly correlated (OECD/PISA 2002). Education level was found to positively affect well-being in many studies (cf. Desjardins 2008), dependent on the conceptualization of education and SWB (Michalos 2008).

Males and females significantly differ concerning many of the described processes and properties. For example, females tend to be better in reading, males tend to excel more in math. Gender differences were also found in the ways adolescents access social and personal resources, for example females seem to make better use of objectified cultural capital (Hupka-Brunner et al. 2011). This may also explain gender differences in SWB (Kroll 2010; Tesch-Römer et al. 2007).

Educational and occupational success depends on previous attainments and may thus be conceived of as a cumulative advantage process (cf. DiPrete and Eirich 2006). Educational and occupational positions at each observed point in time may serve as a potential for further educational and occupational success. Educational credentials and occupational positions may be conceived of as a form of institutionalized cultural capital. Especially in educational systems with strong tracking and highly specialized vocational training, as is the case in Switzerland, previously obtained educational credentials are predictive of further steps in the educational and occupational career. Thus, a certain degree of state dependence (Heckman and Borjas 1980) is likely to be observed. Similarly, one of the best predictors of well-being is well-being previously measured.

\footnotetext{
1 Dual VET refers to the most common form of VET programs in Switzerland, where students spend some days of the week at a vocational school and some day at a host company.
} 
The extent to which certain achievements are thought of as educational or occupational success depends on the space of available and perceived opportunities. These vary across national educational systems. Of prime importance is thus their composition. Educational systems with many selection processes and early tracking seem to reinforce social inequalities as a result of the cumulative impacts of existing social inequalities (Hillmert and Mayer 2004). The varying strength of the impact of social background is often explained by structural characteristics of the educational system (Breen and Jonsson 2000; Kronig 2007). The structuring of educational systems does not only vary across nations. In federal countries, variation is additionally observable on regional and administrative levels. For Switzerland, especially the French-speaking and German-speaking regions differ from each other with regard to educational and occupational mobility. In the former region, there is a tendency to enroll at all costs in academic high school. Consequences may include having to repeat classes or having to drop out to a lower educational track (Amos 1994, 1995; OPET 2008). Also, there is evidence that the French-speaking region of Switzerland exhibits lower levels of well-being than the German-speaking region (Semmer et al. 2005).

In sum, social background, individual factors, structural processes, and institutional context contribute in manifold ways to the reciprocal relationship between educational and occupational success and well-being. We will thus include these elements in our analysis.

\section{Data and Methods}

\subsection{Data}

We examine the interplay between educational achievement, occupational success, and well-being by analyzing panel data from the Transition from Education to Employment Project (TREE). TREE $(2008)^{2}$ focuses on the post-compulsory educational and labor market pathways of the PISA 2000 cohort in Switzerland. It is based on a sample of 6,343 young people who left compulsory schooling in 2000. Annual panel waves were conducted from 2001 (wave 1) to 2006 (wave 6). At the time of the first interview, the age range of the middle fifty percent of the youths was between 16.5 and 17.3 years. We used full information maximum likelihood with a robust (MLR) estimator (Raykov 2005). The data set used for the final model contained 5,327 cases.

\subsection{Operational Definitions}

\subsubsection{Social Comparison}

For each wave, differences between parental institutionalized cultural capital, operationalized as educational position (ISCED 97), and their offspring's educational or occupational position were calculated. The focus on education was chosen as the youths in the sample are no more than 4 years in the labor force at the end of the observational period (wave 6). The success differentials calculated may be positive (adolescent's educational or occupational position $>$ parental educational position), stable (adolescent's educational or occupational position $=$ parental educational position), or negative (adolescent's

\footnotetext{
2 TREE has been running since 2000 and has been funded by the Swiss National Science Foundation, the University of Basel, the Swiss Federal Office of Statistics, the Federal Office of Professional Education and Technology, and the cantons of Berne, Geneva, and Ticino.
} 
educational or occupational position $<$ parental educational position). These differentials are conceived of as qualitative differences. For example, parents with compulsory education as highest education level (ISCED 97, I) will create the same positive success differential, regardless of whether their offspring is enrolled in a VET program or university. The averaged proportions over all waves are $39.1 \%$ for positive differentials, $40.4 \%$ for stable differentials, and $20.5 \%$ for negative differentials (cf. Appendix 2 for exact proportions over time).

\subsubsection{Well-Being}

Well-being is operationalized as a positive attitude toward life. This aspect of well-being is affected by processes related to cognition and affect (Grob et al. 1996: 786; Diener 1984). A positive attitude toward life is improved when aspirations and developmental tasks are met or exceeded (Evans 1994). It is measured at each wave by a five item construct developed by Grob et al. (1991). The items are: "My future looks bright", "I am happy to live", "I am happy with the way my life plan unfolds", "Whatever happens, I can see the positive side of it", and "My life seems to be meaningful". Each item is rated from 1 (totally disagree) to 6 (totally agree). The average alpha coefficient for this scale is 0.884 (average over all waves), its Tucker-Lewis Index (Tucker and Lewis 1973) per wave ranges from 0.879 to 0.919 , and is 0.953 for an autoregressive model over 6 waves allowing for autocorrelation.

State and path dependence of educational and occupational success and well-being will be accounted for by statistical means (cf. Sect. 3.3).

The following variables and scales represent social background, individual factors, and institutional context (as described in Sect. 2.3). They were all measured in the PISA 2000 survey and are internationally tested (Adams and Wu 2002). Economic capital, symbolic capital, cultural capital, and embodied cultural capital were centered at the grand mean.

\subsubsection{Economic Capital}

Economic capital or wealth is a multi-item variable including different aspects of familial wealth, such as number of cars, bathrooms, computers, and cell phones and whether the adolescents have a room of their own $(\mathrm{SD}=0.81)$.

\subsubsection{Symbolic Capital}

Symbolic capital is measured by the International Socioeconomic Index of Occupational Status, derived from information on the parents' main job. The highest value of the parents was chosen (HISEI; SD = 16.28).

\subsubsection{Cultural Capital}

The familial cultural capital is operationalized as objectified cultural capital as a multi-item composite variable. Information on amount of books, paintings, etc. was combined with more detailed information on the kind of the cultural goods, e.g., whether the household owns classical literature and books of poems $(\mathrm{SD}=6.31)$. 


\subsubsection{Embodied Cultural Capital}

Embodied cultural capital was operationalized with a measure of reading literacy. This measure combines three aspects of reading: "Retrieving, interpreting and reflecting upon and evaluating information" (Adams and Wu 2002: 200; SD = 89.00).

\subsubsection{Gender}

As many of the described influential factors are gendered, e.g., girls do better in reading than boys, we control for gender by including an indicator for being female (54.3\%).

\subsubsection{Structure of Educational and Occupational Systems}

Educational and occupational systems are likely to differ in many aspects on various levels, down to the community level. We included a dummy for the French and Italianspeaking regions of Switzerland (i.e., Latin; 53.2\%).

\subsection{Analysis}

An autoregressive cross-lagged mixture model framework is used to test the implied reciprocal relationship between educational achievement, occupational success, and wellbeing. Thereby we are also able to capture the dynamic of this interplay over time. As previous research shows, episodes of successful and unsuccessful mobility will not be evenly distributed over the observed period (Mare 1980). Our analytical strategy allows for the expected unequal distribution of the research variables over time and the multilevel structure of the data.

The model is a combination of Latent Transition Analysis (Humphreys and Janson 2000; Lazarsfeld 1968; Nylund 2007) and Autoregressive Structural Equation Modeling (Bollen and Long 1993; Curran and Bollen 2001), conditional on a series of time-invariant control variables. In the Latent Transition Analysis part of the model, success differentials are measured as latent classes $\boldsymbol{c}_{\mathrm{n}}$ with fixed outcome categories (personal communication with Linda Muthén 2010; Fig. 1).

Three latent classes are specified for each wave with the classes being adolescents who are successful $\left(u_{n 1}\right)$, stable $\left(u_{n 2}\right)$, or unsuccessful $\left(u_{n 3}\right)$ in comparison to their parents. Theses latent classes are specified to correlate over time to reflect state and path dependence, i.e., we include controls for higher order state dependence (cf. paths connecting $\boldsymbol{c}_{1}$, $\boldsymbol{c}_{2}$, and $\boldsymbol{c}_{3}$ in Fig. 1). In the Autoregressive Structural Equation part of the model, positive attitude toward life for each wave is specified to correlate over time (cf. paths connecting $\mathrm{y}_{1}, \mathrm{y}_{2}$, and $\mathrm{y}_{3}$ in Fig. 1). For reasons of parsimony and to minimize the computational burden, positive attitude toward life is condensed into factor scores for the final model (such that $\mathrm{y}_{\mathrm{n}} \sim \mathrm{N}(0,1)$ ). Both parts of the model are connected with cross-lagged relationships. For example, success differentials $c_{1}$ are specified to impact on positive attitude toward life $\mathrm{y}_{2}$ via the intercept of positive attitude toward life $\mathrm{i}_{y_{2}}$ and the slope of the autoregressive relationship of positive attitude toward life $s_{y 2}$ (Fig. 2).

Positive attitude toward life $\mathrm{y}_{1}$ is specified to predict the likelihood of membership in one of the three latent classes in $c_{2}$ via a logit function (Fig. 1). Intercepts and slopes between and within classes are freely estimated, i.e. intercepts $i_{y n}$ and slopes $s_{y n}$ of the autoregressive parts of the model for a positive attitude toward life are allowed to vary between classes and over time and reflect the dynamics under $H_{1}$ (cf. Fig. 1). Slopes $\mathbf{s}_{x \mathrm{n}}$ for 


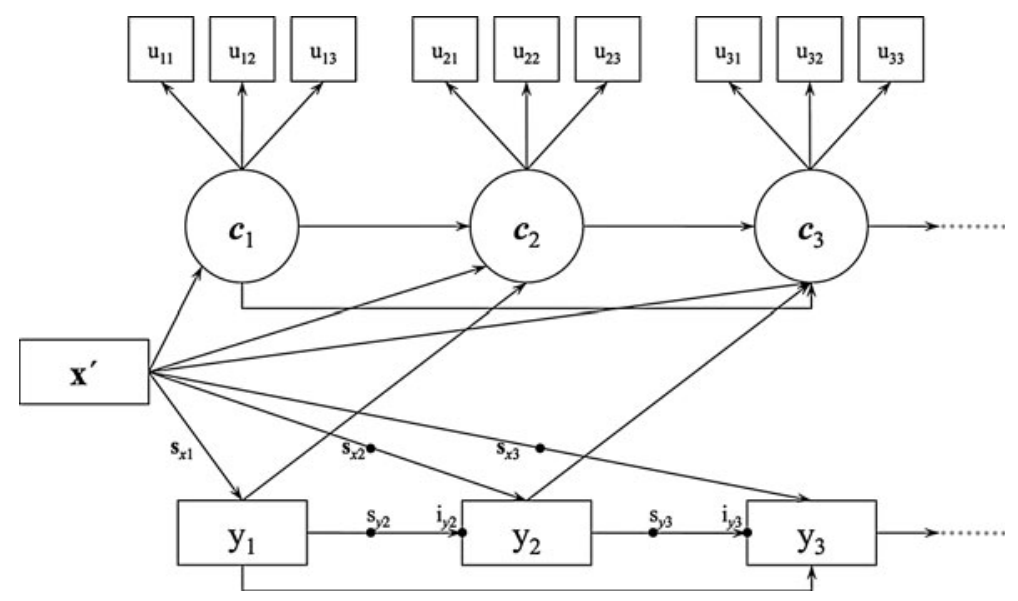

Fig. 1 Graphical representation of the model for the first three panel waves (black dots refer to class-variant effects; cf. Fig. 2)

Fig. 2 Graphical representation of class-variant effects of wave 1 success differentials $c_{1}$ on wave 2 well-being $\mathrm{y}_{2}$ via $\mathrm{s}_{x 2}, \mathrm{~s}_{y 2}$, and $\mathrm{i}_{y 2}$ (cf. black dots in Fig. 1)

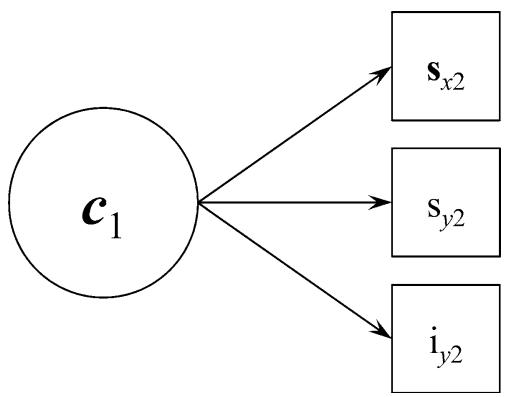

the time-invariant control variables $\mathbf{x}^{\prime}$ are allowed to vary between classes and over time (Figs. 1, 2).

This model estimates the effects of success differentials $\boldsymbol{c}$ on well-being, measured as a positive attitude toward life, $\mathrm{y}_{\mathrm{n}}\left(\mathrm{H}_{1}\right)$, controlling for time-invariant variables $\mathbf{x}^{\prime}$ and autoregressive relationships. The effects of well-being y on success differentials $\boldsymbol{c}_{\mathrm{n}}$ may be estimated controlling for time-invariant variables $\mathbf{x}^{\prime}$ and autoregressive relationships $\left(\mathrm{H}_{2}\right)$. To compare change over time for successful and unsuccessful adolescents, absolute levels of well-being and slopes of the independent variables were set equal at wave 1 . We employ a robust maximum likelihood estimator to account for problems of autocorrelation and biased estimates of standard errors. The estimates are obtained using Montecarlo integration.

\section{Results}

Two hypotheses are tested to examine the reciprocal relationship between educational and occupational success and well-being: First, that adolescents who are successful in 
comparison to their parents experience an increase in well-being over time, whereas unsuccessful adolescents' well-being is negatively affected (i.e., adolescents' success differentials produce contrastive well-being outcomes over time). Second, adolescents' well-being is positively associated with the probability of being successful. Both hypotheses are tested within one single autoregressive cross-lagged mixture model. Absolute fit indices based on Chi-square are inadequate in the given context (McLachlan and Peel 2000). Instead, log likelihood difference tests were used without bootstrapping (ibid.) as class membership was fixed (cf. Appendix 1).

Table 1 shows the MLR estimates for predictors of well-being over six waves $\left(t_{1}-t_{6}\right)$ and three latent classes: adolescents who are successful, stable, or unsuccessful in comparison to their parents. The estimates for predictors of well-being were allowed to vary between classes and over time (except for $t_{1}$ ). Well-being, operationalized as positive attitude toward life, is differently affected over time and across classes. By design, all adolescents initially exhibit identical estimates for predictors of well-being. Most of the variance in well-being is accounted for by autoregressive relationships. ${ }^{3}$ They were found to differ moderately between classes. ${ }^{4}$ According to the hypothesis, successful adolescents, e.g., adolescents who have attained a higher education level than their parents, experience positive effects on their well-being compared to unsuccessful adolescents, e.g., adolescents who did not achieve the same education level as their parents. Indeed, the slopes for the autoregressive relationships differ between successful and unsuccessful adolescents (cf. Well-being_ $t_{n}$ as predictor in Table 1). However, the pattern of difference is not systematic. At $t_{4}$ and $t_{6}$ successful adolescents exhibit a steeper slope than unsuccessful adolescents. Being successful allows them to increase their well-being compared to unsuccessful adolescents. At $t_{2}, t_{3}$, and $t_{5}$ unsuccessful youths seem to be more advantaged concerning well-being. However, none of these differences are significant. In this respect, there is no evidence for contrastive mechanisms of success on well-being. Nonetheless, other predictors of well-being hint at contrastive mechanisms. For example, only successful adolescents use their parents' economic capital $\left(t_{3}\right.$ and $\left.t_{5}\right)$ to increase their well-being. Female adolescents' well-being is initially lower compared to males. This does not change over time for successful and unsuccessful adolescents. As with gender, youths in the Latin region, i.e. in the French and Italian-speaking regions of Switzerland, appear to be generally worse off in terms of well-being compared to the German-speaking region. Interestingly this effect seems to continue over time, but to a different degree for successful and unsuccessful adolescents. Successful adolescents experience a less negative effect on their well-being compared to unsuccessful adolescents $\left(t_{3}, t_{4}, t_{5}\right.$, and $\left.t_{6}\right)$.

In sum, there is mixed evidence to support $\mathrm{H}_{1}$. Social comparison between adolescents and parents in terms of educational and occupational success affects the adolescents' wellbeing not systematically, when assuming contrastive mechanisms. More precisely, there are only few short term effects observable. It turns out that autoregressive relationships predict most of the variance of well-being. Being female or living in the Latin region of Switzerland are initially associated with decreasing well-being, taking other individual and social factors into account. Over time, successful youths' well-being appears to be less affected by living in the Latin region of Switzerland. Also, they seem to make use of their parents' wealth to increase their well-being. Generally, the well-being patterns of adolescents who are successful, stable, or unsuccessful in comparison to their parents differ

\footnotetext{
${ }^{3}$ Higher order autocorrelation was assumed to be constant over classes. Not shown in Table 1. Average autocorrelation is 0.13 over all waves.

${ }^{4}$ Intercepts of positive attitude toward life differ also over time and between classes, but not significantly.
} 
Table 1 Estimates for predictors of well-being $(n=5,327)$

\begin{tabular}{|c|c|c|c|c|c|c|}
\hline & \multicolumn{2}{|l|}{ Successful } & \multicolumn{2}{|l|}{ Stable } & \multicolumn{2}{|c|}{ Unsuccessful } \\
\hline & $\mathrm{b}$ & $\mathrm{SE}(\mathrm{b})$ & $\mathrm{b}$ & $\mathrm{SE}(\mathrm{b})$ & $\mathrm{b}$ & $\mathrm{SE}(\mathrm{b})$ \\
\hline \multicolumn{7}{|l|}{$\mathrm{t}_{1 \_ \text {well-being }}$} \\
\hline Cultural cap. & 0.00 & 0.00 & 0.01 & 0.00 & 0.01 & 0.00 \\
\hline Symbolic cap. & 0.05 & 0.02 & 0.00 & 0.00 & 0.00 & 0.00 \\
\hline Economic cap. & $-0.26^{* *}$ & 0.03 & $0.05^{* *}$ & 0.02 & $0.05 * *$ & 0.02 \\
\hline Female & $-0.33 * * *$ & 0.03 & $-0.26^{* * *}$ & 0.03 & $-0.26^{* * *}$ & 0.03 \\
\hline Latin & $0.00 * * *$ & 0.00 & $-0.33 * * *$ & 0.03 & $-0.33^{* * *}$ & 0.03 \\
\hline Reading lit. & 0.31 & 0.02 & 0.00 & 0.00 & 0.00 & 0.00 \\
\hline Intercept & $0.01 * * *$ & 0.00 & $0.31 * * *$ & 0.02 & $0.31 * * *$ & 0.02 \\
\hline \multicolumn{7}{|l|}{$\mathrm{t}_{2}$ _well-being } \\
\hline Cultural cap. & 0.00 & 0.00 & 0.00 & 0.00 & 0.00 & 0.01 \\
\hline Symbolic cap. & 0.00 & 0.00 & 0.02 & 0.02 & 0.00 & 0.00 \\
\hline Economic cap. & -0.01 & 0.03 & -0.03 & 0.04 & -0.01 & 0.03 \\
\hline Female & -0.06 & 0.04 & $-0.12^{* *}$ & 0.04 & 0.01 & 0.06 \\
\hline Latin & $-0.09 *$ & 0.04 & 0.00 & 0.00 & -0.11 & 0.06 \\
\hline Reading lit. & 0.00 & 0.00 & $0.62 * * *$ & 0.03 & 0.00 & 0.00 \\
\hline Well-being_ $\mathrm{t}_{1}$ & $0.57 * * *$ & 0.03 & 0.06 & 0.03 & $0.60 * * *$ & 0.04 \\
\hline Intercept & 0.06 & 0.04 & 0.00 & 0.00 & 0.05 & 0.05 \\
\hline \multicolumn{7}{|l|}{$\mathrm{t}_{3 \text { _well-being }}$} \\
\hline Cultural cap. & 0.00 & 0.00 & 0.01 & 0.00 & 0.00 & 0.01 \\
\hline Symbolic cap. & 0.01 & 0.00 & 0.00 & 0.00 & 0.00 & 0.00 \\
\hline Economic cap. & -0.04 & 0.03 & -0.02 & 0.03 & 0.01 & 0.04 \\
\hline Female & $-0.17 * * *$ & 0.04 & $-0.10^{*}$ & 0.04 & 0.02 & 0.07 \\
\hline Latin & $0.00 *$ & 0.04 & $-0.15^{* * *}$ & 0.04 & $-0.17 * *$ & 0.07 \\
\hline Reading lit. & $0.53 * * *$ & 0.00 & 0.00 & 0.00 & 0.00 & 0.00 \\
\hline Well-being_ $t_{2}$ & $0.12 * * *$ & 0.02 & $0.52 * * *$ & 0.03 & $0.52 * * *$ & 0.04 \\
\hline Intercept & 0.00 & 0.04 & $0.12^{* *}$ & 0.04 & 0.09 & 0.05 \\
\hline \multicolumn{7}{|l|}{$\mathrm{t}_{4 \_ \text {well-being }}$} \\
\hline Cultural cap. & 0.00 & 0.00 & 0.00 & 0.00 & 0.00 & 0.01 \\
\hline Symbolic cap. & 0.00 & 0.00 & 0.00 & 0.00 & 0.00 & 0.00 \\
\hline Economic cap. & 0.01 & 0.03 & 0.05 & 0.03 & -0.05 & 0.04 \\
\hline Female & -0.04 & 0.04 & 0.00 & 0.04 & -0.08 & 0.06 \\
\hline Latin & $-0.17 * * *$ & 0.04 & $-0.13^{* * *}$ & 0.04 & $-0.22 * * *$ & 0.06 \\
\hline Reading lit. & $0.00 *$ & 0.00 & 0.00 & 0.00 & 0.00 & 0.00 \\
\hline Well-being_t ${ }_{3}$ & $0.53 * * *$ & 0.03 & $0.56^{* * * *}$ & 0.03 & $0.47 * * *$ & 0.04 \\
\hline Intercept & $0.12 * * *$ & 0.04 & 0.06 & 0.04 & $0.17 * * *$ & 0.05 \\
\hline \multicolumn{7}{|l|}{ 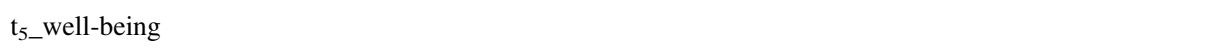 } \\
\hline Cultural cap. & $-0.01 *$ & 0.00 & 0.00 & 0.00 & 0.00 & 0.01 \\
\hline Symbolic cap. & 0.00 & 0.00 & $-0.01 * * *$ & 0.00 & 0.00 & 0.00 \\
\hline Economic cap. & $0.06^{*}$ & 0.03 & 0.01 & 0.03 & -0.03 & 0.04 \\
\hline Female & 0.05 & 0.05 & 0.00 & 0.04 & -0.06 & 0.06 \\
\hline Latin & -0.08 & 0.04 & -0.08 & 0.04 & $-0.26^{* * *}$ & 0.06 \\
\hline Reading lit. & 0.00 & 0.00 & 0.00 & 0.00 & 0.00 & 0.00 \\
\hline
\end{tabular}


Table 1 continued

\begin{tabular}{|c|c|c|c|c|c|c|}
\hline & \multicolumn{2}{|l|}{ Successful } & \multicolumn{2}{|l|}{ Stable } & \multicolumn{2}{|c|}{ Unsuccessful } \\
\hline & $\mathrm{b}$ & $\mathrm{SE}(\mathrm{b})$ & $\mathrm{b}$ & $\mathrm{SE}(\mathrm{b})$ & $\mathrm{b}$ & $\mathrm{SE}(\mathrm{b})$ \\
\hline Well-being_t $t_{4}$ & $0.52 * * *$ & 0.03 & $0.56^{* * *} *$ & 0.03 & $0.54 * * *$ & 0.04 \\
\hline Intercept & -0.02 & 0.05 & 0.04 & 0.04 & $0.10^{*}$ & 0.05 \\
\hline \multicolumn{7}{|l|}{$\mathrm{t}_{6 \_ \text {well-being }}$} \\
\hline Cultural cap. & 0.00 & 0.00 & 0.00 & 0.00 & 0.01 & 0.01 \\
\hline Symbolic cap. & 0.00 & 0.00 & 0.00 & 0.00 & 0.00 & 0.00 \\
\hline Economic cap. & 0.06 & 0.03 & 0.02 & 0.03 & 0.03 & 0.04 \\
\hline Female & -0.04 & 0.04 & 0.02 & 0.04 & 0.01 & 0.06 \\
\hline Latin & $-0.13 * *$ & 0.04 & $-0.17 * * *$ & 0.05 & $-0.18 * *$ & 0.07 \\
\hline Reading lit. & 0.00 & 0.00 & 0.00 & 0.00 & 0.00 & 0.00 \\
\hline Well-being_t $\mathrm{t}_{5}$ & $0.55^{* * *}$ & 0.03 & $0.57 * * *$ & 0.03 & $0.54 * * *$ & 0.05 \\
\hline Intercept & $0.11 *$ & 0.04 & 0.04 & 0.04 & 0.09 & 0.06 \\
\hline
\end{tabular}

*** $p<0.001 ; * * p<0.01 ; * p<0.05$

moderately. We now examine, whether there are effects in the other direction of the reciprocal relationship between well-being and educational and occupational success, i.e., whether well-being affects the probability of being successful.

Table 2 shows the MLR logit estimates for predictors of membership in two latent classes, adolescents who are successful and stable in comparison to their parents, over six waves $\left(t_{1}\right.$ to $\left.t_{6}\right)$. Unsuccessful adolescents are specified as reference category.

First, we will highlight some features of the table that are central to the examined reciprocity: importantly, there is a high degree of first order state dependence over time (Table 2). In other words, adolescents who are successful in comparison to their parents at one observational point are likely to be in the same state at the next observation holding all other predictors constant. For example, adolescents who were successful at $t_{1}$ exhibit an odds ratio of $3,579.58$ to be in the same state at $t_{2}$. Second order state dependence, i.e., the dependence of the adolescents' states between $t_{n}$ and $t_{n+2}$, is almost as strong as first order state dependence, whereas third and fourth order state dependence do not exhibit a similarly consistent pattern. However, fifth order state dependence is such that being successful at the first observation $\left(\mathrm{t}_{1}\right)$ strongly predicts being successful at the last observation $\left(\mathrm{t}_{6}\right.$; odds ratio $=4.95$ ). The same patterns of state dependence hold for adolescents who are neither successful nor unsuccessful in comparison to their parents. Also here, there is significant fifth order state dependence $\left(\mathrm{t}_{6}\right.$; odds ratio $\left.=2.59\right)$.

Controlling for all other predictors and autoregressive relationships, well-being increases the probability of being successful at $t_{2}, t_{5}$, and $t_{6}$ (odds ratios: 1.34, 1.19, and 1.24). That is, although powerful predictors are present, well-being contributes to success. For example, at $t_{1}$ and $t_{4}$, to live in the French or Italian-speaking region of Switzerland increases the likelihood of being successful in comparison to one's parents (odds ratio: 2.30; Table 2). However, at $t_{3}, t_{5}$, and $t_{6}$ this becomes a risk factor for success. To be female is predictive of success at $t_{1}, t_{2}$, and $t_{3}$ but a risk factor at $t_{6}$. Also good reading skills appear to foster success at $t_{1}, t_{4}$, and $t_{6}$. Economic capital is detrimental to success at $t_{1}$ and $t_{2}$, symbolic capital at $t_{1}$ to $t_{5}$, and cultural capital at $t_{1}$. These results indicate that well-being is an individual resource among others that contributes to educational and occupational success. It seems to have effects especially between the major transitions for 
Table 2 Estimates for predictors of positive (success) and neutral success (stability) differentials (reference category: negative success differential; $\mathrm{n}=5,327$ )

\begin{tabular}{|c|c|c|c|c|c|c|c|c|}
\hline & \multicolumn{4}{|c|}{ t1_success } & \multicolumn{4}{|c|}{ t1_stability } \\
\hline & $\mathrm{b}$ & OR & SE (b) & sig. & $\mathrm{b}$ & OR & SE (b) & sig. \\
\hline Latin & 0.83 & 2.30 & 0.08 & $* * *$ & 0.50 & 1.65 & 0.08 & $* * *$ \\
\hline Female & 0.30 & 1.35 & 0.08 & $* * *$ & 0.12 & 1.12 & 0.08 & \\
\hline Reading lit. & 0.01 & 1.01 & 0.00 & $* * *$ & 0.00 & 1.00 & 0.00 & $* * *$ \\
\hline Economic cap. & -0.27 & 0.76 & 0.05 & $* * *$ & -0.19 & 0.83 & 0.05 & $* * *$ \\
\hline Symbolic cap. & -0.03 & 0.97 & 0.00 & $* * *$ & -0.01 & 1.00 & 0.00 & \\
\hline Cultural cap. & -0.02 & 0.98 & 0.01 & $*$ & 0.00 & 1.00 & 0.01 & \\
\hline \multirow[t]{2}{*}{ Constant } & 0.00 & 1.00 & 0.07 & & 0.46 & 1.59 & 0.07 & $* * *$ \\
\hline & \multicolumn{4}{|c|}{ t2_success } & \multicolumn{4}{|c|}{ t2_stability } \\
\hline Latin & -0.03 & 0.97 & 0.18 & & 0.59 & 1.81 & 0.15 & $* * *$ \\
\hline Female & 1.14 & 3.11 & 0.17 & $* * *$ & 0.69 & 2.00 & 0.14 & $* * *$ \\
\hline Reading lit. & 0.00 & 1.00 & 0.00 & & 0.00 & 1.00 & 0.00 & $* * *$ \\
\hline Economic cap. & -0.29 & 0.75 & 0.11 & $* *$ & -0.21 & 0.81 & 0.09 & $*$ \\
\hline Symbolic cap. & -0.05 & 0.96 & 0.01 & $* * *$ & -0.01 & 0.99 & 0.01 & $* *$ \\
\hline Cultural cap. & -0.01 & 0.99 & 0.02 & & 0.00 & 1.00 & 0.01 & \\
\hline Well-being_t ${ }_{1}$ & 0.29 & 1.34 & 0.10 & $* *$ & 0.22 & 1.24 & 0.08 & $* *$ \\
\hline t1_success & 8.18 & $3,579.58$ & 0.38 & $* * *$ & 2.93 & 18.67 & 0.32 & $* * *$ \\
\hline t1_stability & 5.21 & 183.64 & 0.27 & $* * *$ & 4.96 & 142.45 & 0.18 & $* * *$ \\
\hline \multirow[t]{2}{*}{ Constant } & -4.05 & 0.02 & 0.23 & $* * *$ & -2.03 & 0.13 & 0.14 & $* * *$ \\
\hline & \multicolumn{4}{|c|}{ t3_success } & \multicolumn{4}{|c|}{ t3_stability } \\
\hline Latin & -1.23 & 0.29 & 0.26 & $* * *$ & -0.31 & 0.74 & 0.21 & \\
\hline Female & 0.92 & 2.51 & 0.23 & $* * *$ & 0.44 & 1.56 & 0.18 & $*$ \\
\hline Reading lit. & 0.00 & 1.00 & 0.00 & & 0.00 & 1.00 & 0.00 & \\
\hline Economic cap. & -0.29 & 0.75 & 0.16 & & -0.18 & 0.83 & 0.13 & \\
\hline Symbolic cap. & -0.02 & 0.98 & 0.01 & $*$ & -0.01 & 0.99 & 0.01 & \\
\hline Cultural cap. & -0.01 & 0.99 & 0.02 & & 0.00 & 1.00 & 0.02 & \\
\hline Well-being_t $t_{2}$ & 0.25 & 1.28 & 0.14 & & 0.03 & 1.03 & 0.12 & \\
\hline t2_success & 7.02 & $1,113.21$ & 0.42 & $* * *$ & 3.25 & 25.74 & 0.46 & $* * *$ \\
\hline t2_stability & 3.66 & 38.94 & 0.41 & $* * *$ & 5.44 & 229.29 & 0.28 & $* * *$ \\
\hline t1_success & 2.99 & 19.95 & 0.49 & $* * *$ & 1.17 & 3.23 & 0.57 & $*$ \\
\hline t1_stability & 1.22 & 3.40 & 0.31 & $* * *$ & 0.91 & 2.49 & 0.28 & $* * *$ \\
\hline \multirow[t]{2}{*}{ Constant } & -4.41 & 0.01 & 0.35 & $* * *$ & -2.65 & 0.07 & 0.17 & $* * *$ \\
\hline & \multicolumn{4}{|c|}{ t4_success } & \multicolumn{4}{|c|}{ t4_stability } \\
\hline Latin & 1.31 & 3.72 & 0.17 & $* * *$ & 0.70 & 2.01 & 0.12 & $* * *$ \\
\hline Female & -0.02 & 0.98 & 0.15 & & 0.05 & 1.05 & 0.11 & \\
\hline Reading lit. & -0.01 & 1.00 & 0.00 & $* * *$ & 0.00 & 1.00 & 0.00 & $* * *$ \\
\hline Economic cap. & -0.04 & 0.96 & 0.10 & & 0.02 & 1.02 & 0.08 & \\
\hline Symbolic cap. & -0.02 & 0.98 & 0.01 & $* * *$ & -0.01 & 0.99 & 0.00 & $* *$ \\
\hline Cultural cap. & 0.01 & 1.01 & 0.01 & & 0.00 & 1.00 & 0.01 & \\
\hline
\end{tabular}


Table 2 continued

\begin{tabular}{|c|c|c|c|c|c|c|c|c|}
\hline \multirow[b]{2}{*}{ Well-being_ $t_{3}$} & \multicolumn{4}{|c|}{ t4_success } & \multicolumn{4}{|c|}{ t4_stability } \\
\hline & 0.11 & 1.11 & 0.08 & & 0.07 & 1.07 & 0.06 & \\
\hline t3_success & 6.26 & 520.61 & 0.71 & $* * *$ & 2.50 & 12.22 & 0.38 & $* * *$ \\
\hline t3_stability & 2.73 & 15.36 & 0.70 & $* * *$ & 3.77 & 43.21 & 0.31 & $* * *$ \\
\hline t2_success & 2.62 & 13.78 & 0.57 & $* * *$ & 1.36 & 3.88 & 0.38 & $* * *$ \\
\hline t2_stability & 1.10 & 3.00 & 0.55 & $*$ & 1.51 & 4.52 & 0.32 & $* * *$ \\
\hline t1_success & -0.89 & 0.41 & 0.33 & $* *$ & -0.44 & 0.64 & 0.35 & \\
\hline t1_stability & -0.30 & 0.74 & 0.28 & & -1.01 & 0.37 & 0.27 & $* * *$ \\
\hline \multirow[t]{2}{*}{ Constant } & -5.68 & 0.00 & 0.40 & $* * *$ & -2.87 & 0.06 & 0.17 & $* * *$ \\
\hline & \multicolumn{4}{|c|}{ t5_success } & \multicolumn{4}{|c|}{ t5_stability } \\
\hline Latin & -0.59 & 0.55 & 0.14 & $* * *$ & -0.42 & 0.65 & 0.11 & $* * *$ \\
\hline Female & 0.18 & 1.20 & 0.14 & & 0.09 & 1.09 & 0.10 & \\
\hline Reading lit. & 0.00 & 1.00 & 0.00 & & 0.00 & 1.00 & 0.00 & \\
\hline Economic cap. & -0.07 & 0.93 & 0.10 & & -0.12 & 0.89 & 0.07 & \\
\hline Symbolic cap. & -0.02 & 0.98 & 0.01 & $* * *$ & 0.00 & 1.00 & 0.00 & \\
\hline Cultural cap. & -0.01 & 0.99 & 0.01 & & 0.01 & 1.01 & 0.01 & \\
\hline Well-being_t 4 & 0.17 & 1.19 & 0.07 & $*$ & 0.07 & 1.07 & 0.05 & \\
\hline t4_success & 2.75 & 15.60 & 0.25 & $* * *$ & 0.91 & 2.48 & 0.21 & $* * *$ \\
\hline t4_stability & 1.09 & 2.96 & 0.20 & $* * *$ & 1.41 & 4.09 & 0.14 & $* * *$ \\
\hline t3_success & 3.25 & 25.84 & 0.64 & $* * *$ & 0.85 & 2.33 & 0.28 & $* *$ \\
\hline t3_stability & 2.13 & 8.42 & 0.58 & $* * *$ & 1.84 & 6.28 & 0.24 & $* * *$ \\
\hline t2_success & 1.88 & 6.55 & 0.51 & $* * *$ & 1.49 & 4.43 & 0.32 & $* * *$ \\
\hline t2_stability & 0.62 & 1.86 & 0.45 & & 0.09 & 1.10 & 0.26 & \\
\hline t1_success & 0.39 & 1.47 & 0.34 & & -0.14 & 0.87 & 0.26 & \\
\hline t1_stability & 0.59 & 1.80 & 0.29 & $*$ & 0.35 & 1.42 & 0.20 & \\
\hline \multirow[t]{2}{*}{ Constant } & -4.99 & 0.01 & 0.38 & $* * *$ & -1.88 & 0.15 & 0.13 & $* * *$ \\
\hline & \multicolumn{4}{|c|}{ t6_success } & \multicolumn{4}{|c|}{ t6_stability } \\
\hline Latin & -0.37 & 0.69 & 0.16 & $*$ & -0.29 & 0.75 & 0.12 & $*$ \\
\hline Female & -0.31 & 0.74 & 0.15 & $*$ & -0.12 & 0.89 & 0.12 & \\
\hline Reading lit. & 0.00 & 1.00 & 0.00 & $* *$ & 0.00 & 1.00 & 0.00 & \\
\hline Economic cap. & -0.08 & 0.93 & 0.10 & & -0.01 & 0.99 & 0.07 & \\
\hline Symbolic cap. & -0.01 & 0.99 & 0.01 & & 0.01 & 1.01 & 0.00 & $*$ \\
\hline Cultural cap. & -0.02 & 0.98 & 0.01 & & 0.00 & 1.00 & 0.01 & \\
\hline Well-being_ $t_{5}$ & 0.21 & 1.23 & 0.08 & $*$ & 0.10 & 1.10 & 0.06 & \\
\hline t5_success & 3.00 & 20.03 & 0.26 & $* * *$ & 1.24 & 3.46 & 0.24 & $* * *$ \\
\hline t5_stability & 1.10 & 2.99 & 0.19 & $* * *$ & 2.00 & 7.42 & 0.13 & $* * *$ \\
\hline t4_success & 0.53 & 1.70 & 0.34 & & -0.01 & 0.99 & 0.29 & \\
\hline t4_stability & 0.51 & 1.67 & 0.24 & $*$ & 0.29 & 1.34 & 0.17 & \\
\hline t3_success & 3.91 & 49.90 & 0.75 & $* * *$ & 0.76 & 2.13 & 0.33 & $*$ \\
\hline t3_stability & 2.77 & 15.94 & 0.71 & $* * *$ & 0.97 & 2.65 & 0.26 & $* * *$ \\
\hline t2_success & 0.59 & 1.81 & 0.56 & & 0.69 & 2.00 & 0.37 & \\
\hline t2_stability & 0.02 & 1.02 & 0.52 & & -0.17 & 0.85 & 0.30 & \\
\hline
\end{tabular}


Table 2 continued

\begin{tabular}{lcccccccc}
\hline & t5_success & \multicolumn{7}{c}{ t5_stability } \\
\hline t1_success & 1.60 & 4.95 & 0.45 & $* * *$ & 0.24 & 1.27 & 0.33 \\
t1_stability & 1.27 & 3.55 & 0.36 & $* * *$ & 0.95 & 2.59 & 0.21 & $* * *$ \\
Constant & -5.32 & 0.00 & 0.50 & $* * *$ & -1.46 & 0.23 & 0.13 & $* * *$ \\
\hline
\end{tabular}

$* * * p<0.001 ; * * p<0.01 ; * p<0.05$

the majority of the cohort. These findings support $\mathrm{H}_{2}$, that well-being is positively associated with the probability of being successful.

In summary, the selected model proves to fit the data well and indicates a high plausibility of a reciprocal relationship between well-being and educational and occupational success. Effects of success and failure on well-being were not systematically contrastive. Well-being, however, seems to foster educational and occupational success.

\section{Discussion and Conclusion}

The aim of this paper was to examine the reciprocal interplay between educational achievement, occupational success, and well-being over time. Social comparison, as evaluation of one's educational and occupational position with regard to a point of reference, was hypothesized to produce contrastive well-being outcomes. In turn, well-being serves as a resource for successful educational and occupational outcomes.

First, it was tested whether social comparison produces contrastive or contrastive and assimilative well-being outcomes. To this end, a hypothesis pertaining to the former position was formulated. Namely, that adolescents who are successful in comparison to their parents experience an increase in well-being over time, whereas adolescents who are unsuccessful in comparison to their parents experience a decrease in well-being over time. Educational and occupational success, operationalized via social comparisons, did not systematically increase well-being. Conversely, lack of educational and occupational success did not lead to a decrease in well-being as hypothesized. The effects of social comparison were not consistently contrastive. This finding may thus provide evidence for Buunk et al. (1990) position, that social comparison produces contrastive and assimilative outcomes. This could explain why in this paper short term effects of social comparison were not found to be substantial, whereas different types of Bourdieuian capital were significant. For example, successful adolescents seem to be able to make use of parental economic capital to increase their well-being at some periods in their early career.

In turn, it was hypothesized that well-being is positively associated with the probability of being successful. Well-being was argued to be an individual resource with regard to successful educational and occupational outcomes. Well-being was found to increase the probability of being successful in comparison to one's parents at three observation points controlling for a series of types of Bourdieuian capital, gender, and the respective constitution of the educational system. This is in line with some of the literature which conceives of cognitive aspects of well-being as a personal resource in that it allows mastery of challenging situations in educational and occupational contexts (cf. Bandura 1989; Salmela-Aro and Tuominen-Soini 2010). Our findings are especially noteworthy in the presence of sizeable effects for first order state dependence. 
There are limitations to this study. First, our data consists of one school leaver cohort in Switzerland. Second, unmeasured heterogeneity is one of the most serious problems in empirical research of educational and occupational pathways. For example, individuals' capacity and motivation is likely to account for considerable proportions in the variance of educational and occupational success (Breen and Jonsson 2000). In our analysis, we considered this problem and included reading literacy as control. Moreover, a positive attitude toward life may be considered as a concept related to motivation.

In further analyses, a multidimensional concept of quasi-objective success, as outlined in this paper, could be employed to account for the problem of reference point selection in social comparison. Moreover, the empirical results provide the impetus for further research on gender-specific mechanisms with regard to social comparison and well-being. Our findings are in line with other research that shows that young women cope less well with adverse external effects, such as educational or occupational failure, and thus report lower well-being (cf. Salmela-Aro and Tynkkynen 2010). As for males, one could hypothesize that failure in education and occupation may affect well-being negatively as anticipated roles as male breadwinner are at risk (cf. operationalization of well-being). It is still not clear how gender differences in educational success may be explained (Hadjar 2011). Many studies found that females outperformed males during adolescence and young adulthood, e.g., in terms of grades and university degrees (Annen et al. 2011). Yet, women fail to transfer their educational achievement to corresponding occupational positions (Magnusson 2009). One of the explanations offered in the literature has to do with fertility, more precisely with lapsing into traditional family models once the first child is born (cf. Strub et al. 2005). However, these arguments will not explain the inequality observed in earlier pathways, as teen motherhood is rare in Switzerland. ${ }^{5}$ It would be of great interest to analyze these relations further. In such a study, self-esteem may explain, whether social comparison generates assimilative or contrastive outcomes.

Based on the findings of our study, youths in transition to adulthood are likely to experience failure at some points in their early careers without encountering adverse effects on their well-being. However, state and path dependence were found to be strong and powerful cumulative advantage processes are at work. Educational systems with strong tracking, as is the case in Switzerland, and dual VET programs limit the permeability of educational and occupational domains. In this context, well-being may be used as an individual resource to create positive success differentials.

Acknowledgments This research was financed by the Swiss National Science Foundation grants 100013_130042 and 10FI13-120796. The authors would like to thank Jean Anthony Grand-GuillaumePerrenoud for proofreading.

\section{Appendix 1}

See Table 3.

\footnotetext{
5 In Switzerland, teenage pregnancy rates are comparably low. Births by mothers of 15 to 19 years accounted for only 1.0\% of all births in Switzerland between 2001 and 2007 (20 to 24 years for 10.3\%; calculations based on Federal Statistical Office data (2011)).
} 


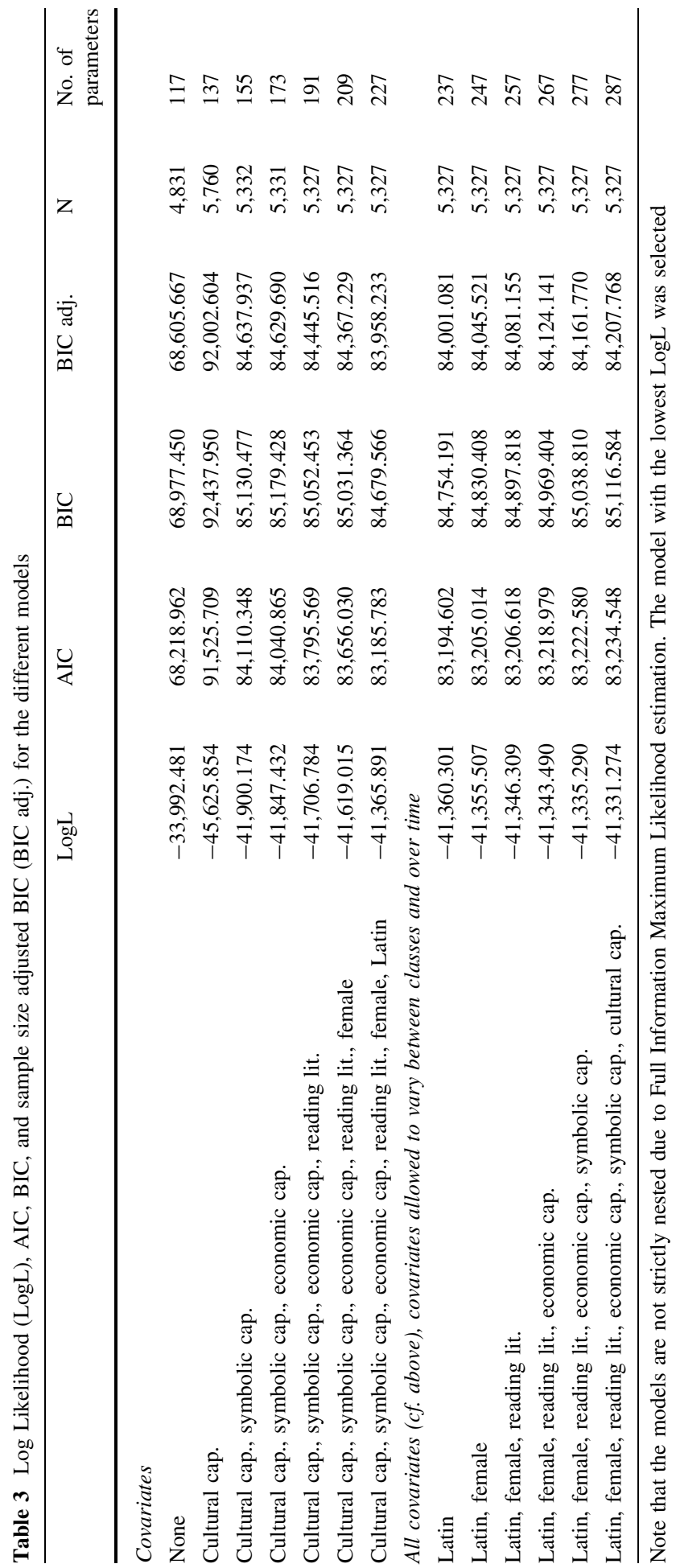




\section{Appendix 2}

See Table 4.

Table 4 Cross-sectional proportions of success differentials in percent $(n=5,327)$

\begin{tabular}{|c|c|c|c|c|c|c|}
\hline Wave & $\mathrm{t}_{1}$ & $t_{2}$ & $t_{3}$ & $\mathrm{t}_{4}$ & $t_{5}$ & $t_{6}$ \\
\hline Successful & 37.4 & 42.2 & 42.1 & 37.4 & 36.3 & 39.2 \\
\hline Stable & 41.7 & 40.3 & 41.1 & 39.3 & 39.4 & 40.5 \\
\hline Unsuccessful & 20.9 & 17.5 & 16.8 & 23.3 & 24.3 & 20.3 \\
\hline
\end{tabular}

\section{References}

Adams, R., \& Wu, M. (Eds.). (2002). PISA 2000 technical report. Paris: OECD/PISA.

Amos, J. (1994). L'entrée en apprentissage: nouvelles modalités. Panorama, 1994(29), 6-8.

Amos, J. (1995). Entrée en apprentissage et nouvelle demande sociale de formation. Panorama, 1994(33), 3-5.

Annen, L., et al. (2011). Swiss education report 2010. Aarau: SKBF, CSRE Swiss Coordination Centre for Research in Education.

Bandura, A. (1989). Regulation of cognitive processes through perceived self-efficacy. Developmental Psychology, 25(5), 729-735.

Bast, J., \& Reitsma, P. (1998). Analyzing the development of individual differences in terms of Matthew effects in reading: Results from a Dutch longitudinal study. Developmental Psychology, 34(6), 1373-1399.

Blau, P. M., \& Duncan, O. D. (1967). The American occupational structure. New York: Wiley.

Blore, J., Stokes, M., Mellor, D., Firth, L., \& Cummins, R. (2011). Comparing multiple discrepancies theory to affective models of subjective wellbeing. Social Indicators Research, 100(1), 1-16.

Blossfeld, H.-P., \& Shavit, Y. (1993). Persisting barriers. Changes in educational opportunities in thirteen countries. In Y. Shavit \& H.-P. Blossfeld (Eds.), Persistent inequality: Changing educational attainment in thirteen countries. San Francisco: Westview-Press.

Boes, S., Staub, K., \& Winkelmann, R. (2010). Relative status and satisfaction. Economics Letters, 109(3), $168-170$.

Bollen, K. A., \& Long, J. S. (1993). Testing structural equation models (1st ed.). Newbury Park, London, New Dehli: Sage Publications, Inc.

Bourdieu, P. (1977). Cultural reproduction and social reproduction. In J. Karabel (Ed.), Power and Ideology in Education (pp. 487-511). New York: Oxford University Press.

Bourdieu, P. (1979). La distinction. Critique sociale du jugement. Paris: Les éditions de minuit.

Bourdieu, P. (2001). In M. Steinrücke (Ed.), Wie die Kultur zum Bauern kommt über Bildung, Schule und Politik. Hamburg: VSA-Verlag.

Bourdieu, P., \& Passeron, J.-C. (1970). La reproduction eléments pour une théorie du système d'enseignement. Paris: Ed. de Minuit.

Bourdieu, P., \& Passeron, J.-C. (1996). Reproduction in education, society and culture. London: Sage Publications.

Bradburn, N. M. (1969). The structure of psychological well-being. Chicago, IL): Aldine.

Bradley, S., \& Nguyen, A. N. (2004). The school-to-work transition. In G. Johnes \& J. Johnes (Eds.), International handbook on the economics of education (pp. 484-521). Cheltenham, Northampton: Edward Elgar Publishing Ltd.

Breen, R. (Ed.). (2004). Social mobility in Europe. Oxford: Oxford University Press.

Breen, R., \& Goldthorpe, J. H. (1997). Explaining educational differentials: Towards a formal rational action theory. Rationality and Society, 9(3), 275-305.

Breen, R., \& Jonsson, J. O. (2000). Analyzing educational careers: A multinomial transition model. American Sociological Review, 65/5, 754-772. 
Buchholz, S., Hofacker, D., Mills, M., Blossfeld, H.-P., Kurz, K., \& Hofmeister, H. (2009). Life courses in the globalization process: The development of social inequalities in modern societies. European Sociological Review, 25(1), 53-71.

Buunk, B. P., Collins, R., Taylor, S., VanYperen, N., \& Dakof, G. (1990). The Affective consequences of social comparison: Either direction has its ups and downs. Journal of Personality and Social Psychology, 59(6), 1238-1249.

Carver, C. S., \& Scheier, M. F. (1990). Origins and functions of positive and negative affect: A controlprocess view. Psychological Review, 97(1), 19-35.

Crisholm, L., \& Hurrelmann, K. (1995). Adolescence in modern Europe. Pluralized transition patterns and their implications for personal and social risks. Journal of Adolescence, 18, 129-158.

Crocker, J., Thompson, L. L., McGraw, K. M., \& Ingerman, C. (1987). Downward comparison, prejudice, and evaluations of others: Effects of self-esteem and threat. Journal of Personality and Social Psychology, 52(5), 907-916.

Curran, P. J., \& Bollen, K. A. (2001). The best of both worlds: Combining autoregressive and latent curve models. In L. M. Collins \& A. G. Sayer (Eds.), New methods for the analysis of change (pp. 105-136). Washington, DC: American Psychological Association.

Desjardins, R. (2008). Researching the links between education and well-being. European Journal of Education, 43(1), 23-35.

Diener, E. (1984). Subjective well-being. Psychological Bulletin, 95(3), 542-575.

Diener, E. (2009). The science of well-being: The collected works of Ed Diener. Berlin, Germany: Springer.

Diener, E., \& Chan, M. Y. (2011). Happy people live longer: Subjective well-being contributes to health and longevity. Applied Psychology: Health and Well-Being, 3(1), 1-43.

DiPrete, T., \& Eirich, G. (2006). Cumulative advantage as a mechanism for inequality: A review of theoretical and empirical developments. Annual Review of Sociology, 32, 271-297.

Eckersley, R., Wyn, J., \& Wierenga, A. (2006). Flashpoints \& signposts: Pathways to success and wellbeing for Australia's young people. http://www.australia21.org.au/pdf/HPreport.pdf. Accessed 25 August 2009.

Erikson, R., \& Goldthorpe, J. H. (1992). The constant flux a study of class mobility in industrial societies. Oxford: Clarendon Press.

Evans, D. R. (1994). Enhancing quality of life in the population at large. Social Indicators Research, 33(1-3), 47-88.

Federal Statistical Office. (2011). Lebendgeburten nach Alter der Mutter, 1970-2010. http://www.bfs. admin.ch/bfs/portal/de/index/themen/01/06/blank/data/01.Document.67357.xls. Accessed 1 October 2011.

Festinger, L. (1954). A theory of social comparison processes. Human Relations, 7(2), 117-140.

Gibbons, F. X., \& Buunk, B. P. (1999). Individual differences in social comparison: Development of a scale of social comparison orientation. Journal of Personality and Social Psychology, 76(1), 129-142.

Grob, A., Little, T. D., Wanner, B., \& Wearing, A. J. (1996). Adolescents' well-being and perceived control across 14 sociocultural contexts. Journal of Personality and Social Psychology, 71(4), 785-795.

Grob, A., Lüthi, R., Kaiser, F. G., Flammer, A., Mackinnon, A., \& Wearing, A. J. (1991). Berner Fragebogen zum Wohlbefinden Jugendlicher (BFW). Diagnostica, 37(1), 66-75.

Hadjar, A. (Ed.). (2011). Geschlechtsspezifische Bildungsungleichheiten. Wiesbaden: VS Verlag für Sozialwissenschaften.

Haeberlin, U., Imdorf, C., \& Kronig, W. (2004). Von der Schule in die Berufslehre. Untersuchungen zur Benachteiligung von ausländischen und von weiblichen Jugendlichen bei der Lehrstellensuche. Bern, Stuttgart, Wien: Haupt Verlag.

Havighurst, R. J., Bowman, P., Liddle, G., Mattens, C., \& Perce, J. (1962). Growing up in River City. New York: Wiley.

Heckman, J. J., \& Borjas, G. J. (1980). Does unemployment cause future unemployment? Definitions, questions and answers from a continuous time model of heterogeneity and state dependence. Economica. Economica, 47(187), 247-283.

Hillmert, S., \& Mayer, K. U. (Eds.). (2004). Geboren 1964 und 1971: Neuere Untersuchungen zu Ausbildungs- und Berufschancen in Westdeutschland. Wiebaden: VS Verlag für Sozialwissenschaften.

Humphreys, K., \& Janson, H. (2000). Latent transition analysis with covariates, nonresponse, summary statistics and diagnostics: Modelling children's drawing development. Multivariate Behavioral Research, 35(1), 89-118.

Hupka-Brunner, S., Samuel, R., Huber, E., \& Bergman, M. M. (2011). Geschlechterungleichheiten im intergenerationalen Bildungstransfer in der Schweiz. In A. Hadjar (Ed.), Geschlechtsspezifische Bildungsungleichheiten (pp. 77-98). Wiesbaden: VS Verlag für Sozialwissenschaften. 
Kim, S., \& Kim, H. (2008). Does cultural capital matter? Cultural divide and quality of life. Social Indicators Research, 93(2), 295-313.

Krais, B. (1983). Bildung als Kapital. Neue Perspektiven für die Analyse der Sozialstruktur? In R. Kreckel (Ed.), Soziale Ungleichheiten (pp. 201-220). Göttingen: Verlag Otto Schwartz.

Kroll, C. (2010). Different things make different people happy: Examining social capital and subjective well-being by gender and parental status. Social Indicators Research, 104(1), 157-177.

Kronig, W. (2007). Die systematische Zufälligkeit des Bildungserfolgs. Theoretische Erklärungen und empirische Untersuchungen zur Lernentwicklung und zur Leistungsbewertung in unterschiedlichen Schulklassen. Bern: Haupt.

Lazarsfeld, P. F. (1968). Latent structure analysis. Boston: Houghton Mifflin Company.

Lazarus, R. S., \& Folkman, S. (1984). Stress, appraisal, and coping. New York: Springer.

Lipset, S. M., \& Bendix, R. (1959). Social mobility in industrial society. London: Heinemann.

Lyubomirsky, S., King, L., \& Diener, E. (2005). The benefits of frequent positive affect: Does happiness lead to success? Psychological Bulletin, 131(6), 803-855.

Magnusson, C. (2009). Gender, occupational prestige, and wages: A test of devaluation theory. European Sociological Review, 25(1), 87-101.

Mare, R. D. (1980). Social background and school continuation decisions. Journal of the American Statistical Association, 75(370), 295-305.

McLachlan, G., \& Peel, D. (2000). Finite mixture models (1st ed.). New York: Wiley.

Merton, R. K., \& Kitt, A. S. (1950). Contributions to the theory of reference group behavior. In R. K. Merton \& P. F. Lazarsfeld (Eds.), Continuities in social research (pp. 40-105). Glencoe (Ill.): The Free Press.

Michalos, A. C. (1985). Multiple discrepancies theory (MDT). Social Indicators Research, 16(4), $347-413$.

Michalos, A. C. (2008). Education, happiness and wellbeing. Social Indicators Research, 87(3), 347-366.

Nylund, K. L. (2007). Latent transition analysis. Los Angeles: University of California.

OECD/PISA (Ed.). (2002). Reading for change. Performance and engagement across countries. Results from Pisa 2000. Programme for International Student Assessment. Paris, France: OECD (Organisation for Economic Co-Operation and Development).

OPET. (2008). Vocational education and training in Switzerland 2008. Facts and figures. Bern, Switzerland: Federal Office for Professional Education and Technology (OPET).

Proctor, C., Linley, P., \& Maltby, J. (2010). Very happy youths: Benefits of very high life satisfaction among adolescents. Social Indicators Research, 98(3), 519-532.

Raykov, T. (2005). Analysis of longitudinal studies with missing data using covariance structure modeling with full-information maximum likelihood. Structural Equation Modeling, 12(3), 493-505.

Roberts, B. W., Caspi, A., \& Moffitt, T. E. (2003). Work experiences and personality development in young adulthood. Journal of Personality and Social Psychology, 84(3), 582-593.

Salmela-Aro, K., \& Tuominen-Soini, H. (2010). Adolescents' life satisfaction during the transition to postcomprehensive education: Antecedents and consequences. Journal of Happiness Studies, 11(6), $683-701$.

Salmela-Aro, K., \& Tynkkynen, L. (2010). Trajectories of life satisfaction across the transition to postcompulsory education: Do adolescents follow different pathways? Journal of Youth and Adolescence, 39(8), 870-881.

Samuel, R., Hupka-Brunner, S., Stalder, B. E., \& Bergman, M. M. (2011). Successful and unsuccessful intergenerational transfer of educational attainment on wellbeing in the Swiss youth cohort TREE. Swiss Journal of Sociology, 37(1), 57-78.

Semmer, N. K., Tschan, F., Elfering, A., Kälin, W., \& Grebner, S. (2005). Young adults entering the workforce in Switzerland: Working conditions and well-being. In H. Kriesi, P. Farago, M. Kohli, \& M. Zarin-Nejadan (Eds.), Contemporary Switzerland (pp. 163-189). New York: Palgrave Macmillan.

Shavit, Y., \& Blossfeld, H.-P. (Eds.). (1993). Persistent inequality. Changing educational attainment in thirteen countries. Boulder, San Francisco \& Oxford: Westview Press.

Shavit, Y., \& Müller, W. (1998). From school to work. A comparative study of educational qualifications and occupational destinations. Oxford: Clarendon Press.

Stanovich, K. E. (1986). Matthew effects in reading: Some consequences of individual differences in the the acquisition of literacy. Reading Research Quarterly, 21(4), 360-407.

Strub, S., Hüttner, E., \& Guggisberg, J. (2005). Arbeitsteilung in Paarhaushalten. Aufteilung von bezahlter und unbezahlter Arbeit in der Schweiz. Neuchâtel: Büro für arbeits- und sozialpolitische Studien BASS.

Suls, J. M., \& Wheeler, L. (Eds.). (2000). Handbook of social comparison. Theory and research. New York: Kluwer Academic/Plenum Publishers.

Tatarkiewicz, W. (1976). Analysis of happiness. The Hague: Nijhoff. 
Tennen, H., \& Affleck, G. (1997). Social comparison as a coping process: A critical review and application to chronic pain disorders. In B. P. Buunk \& F. X. Gibbons (Eds.), Health, coping, and well-being: Perspectives from social comparison theory (pp. 263-298). Mahwah, NJ: Lawrence Erlbaum.

Tesch-Römer, C., Motel-Klingebiel, A., \& Tomasik, M. J. (2007). Gender differences in subjective wellbeing: Comparing societies with respect to gender equality. Social Indicators Research, 85(2), 329-349.

Tucker, L. R., \& Lewis, C. (1973). A reliability coefficient for maximum likelihood factor analysis. Psychometrika, 38(1), 1-10.

Wills, T. A. (1981). Downward comparison principles in social psychology. Psychological Bulletin, 90, $245-271$.

Wilson, E. S. R., \& Benner, L. A. (1971). The effects of self-esteem and situation upon comparison choices during ability evaluation. Sociometry, 34, 381-397.

$\mathrm{Xu}$, J. (2005). Subjective well-being as predictor of mortality, heart disease, and obesity: Prospective evidence from the Alameda County Study. The University of Texas Health Sciences Center at Houston School of Public Health. 